\title{
Maternal Smoking Predicts Larger Waist Circumference and Skin Fold Measures by Middle Childhood
}

\author{
Caroline Fitzpatrick $^{1}$, Tracie A. Barnett $^{2}$ and Linda S. Pagani ${ }^{3}$ \\ ${ }^{1,2,3}$ Centre de Recherche de I'Hôpital Sainte-Justine, Université de Montréal, Canada \\ ${ }^{1,2,3}$ Department of Excercise Science, Concordia University, Canada \\ ${ }^{1,2}$ PERFORM center, Concordia University, Canada
}

Correspondence should be addressed to: Caroline Fitzpatrick; fitzcaro@gmail.com

Received date: 11 December 2013; Accepted date: 8 May 2014; Published date: 5 February 2015

Academic Editor: Óscar García García-Algar

Copyright (C) 2015. Caroline Fitzpatrick, Tracie A. Barnett and Linda S. Pagani. Distributed under Creative Commons CC-BY 4.0

\begin{abstract}
Context: Experimental research using animals and correlational studies with humans provide strong evidence that exposure to gestational cigarette smoke can foster long-term risk for obesity and metabolic syndrome in offspring. Objective: To estimate the association between maternal smoking during pregnancy and the development of adiposity by middle childhood in a sample of typically developing children living in the province of Quebec, Canada. Research Method and Procedure: Participants comprise the Quebec Longitudinal Study of Child Development prospective birth cohort. Mothers of 2010 children reported on smoking during pregnancy when children were 5 months old. Main outcome measures were direct assessment of abdomen, calf, and triceps skin folds at 98 months and waist circumference at 98 and 120 months. Results: Up to $11 \%$ of children experienced heavy exposure to tobacco during gestation. After adjusting for child and family factors, gestational tobacco smoke exposure was prospectively associated with abdomen, calf, and triceps skin folds in mm by 98 months, $B=$ 1.997 ( $\mathrm{CI}=.954-3.040$ ), $B=1.569$ (CI= .685-2.453), and $B=1.141$ (CI= .385-1.897), respectively. Exposure also predicted waist circumference in $\mathrm{cm}$ at 98 and 120 months, $B=1.927(\mathrm{CI}=.634$ $3.22)$ and $B=3.046(\mathrm{CI}=1.81-4.282)$, respectively. Conclusions: This study provides evidence which helps chart the developmental influence of gestational exposure to cigarette smoke on long-term adiposity outcomes. To improve population health, increased efforts should be directed at educating smokers about the potential long-term health hazards association with gestational smoking.
\end{abstract}

Keywords: Gestational smoking; Tobacco; Adiposity; Waist circumference

Cite this Article as: Caroline Fitzpatrick, Tracie A. Barnett and Linda S. Pagani (2015), "Maternal Smoking Predicts Larger Waist Circumference and Skin Fold Measures by Middle Childhood", JMED Research, Vol. 2015 (2015), Article ID 791127, DOI: 10.5171/2015.791127 


\section{Introduction}

There is increasing evidence that insults to the gestational environment may play a role in shaping individual lifelong health trajectories (Barker, 1998; McMillen \& Robinson, 2005). Children exposed to tobacco during gestation are at risk of experiencing a wide range of negative health outcomes. These include premature birth, low-birth weight, decreased lung size, respiratory infections, and cognitive and behavioral problems (Bruin et al., 2008; DiFranza, Aligne, \& Weitzman, 2004; Huizink \& Mulder, 2006; Nordentoft et al., 1996). Studies increasingly provide compelling evidence that in utero exposure to tobacco is associated with greater adiposity in children (Oken, Huh, Taveras, Rich-Edwards, \& Gillman, 2005; Power \& Jefferis, 2002). Greater adiposity, particularly around the waist, represents a reliable risk indicator for metabolic syndrome (Hirschler, Aranda,

The majority of evidence supporting a link between gestational exposure to nicotine and later adiposity has been obtained through animal studies in which random assignment to exposure or control groups is possible (Gao et al., 2005; Holloway, et al., 2007; Holloway et al., 2005). For example, studies with rats have found that maternal exposure to nicotine predicts greater body weight, adiposity, and metabolic illness in exposed offspring. Carefully designed prospective longitudinal designs with humans, which control for potentially confounding factors, are useful for corroborating the findings of animal models. In one longitudinal investigation of prenatal exposure to cigarette smoke, Power and colleagues found that gestational smoke predicts the risk of being overweight in childhood and early adulthood up to the age of 33 (Power \& Jefferis, 2002). In a similar study, Oken and colleagues followed children exposed to gestational tobacco to age 3 . Although they found associations between gestational smoking and later BMI and subscapular and triceps skinfold measures, they found no associations with central
Calcagno, Maccalini, \& Jadzinsky, 2005), which can influence the development of a variety of serious health problems including heart disease, diabetes, and stroke later in life (Alberti, Zimmet, \& Shaw, 2005).

One particularly daunting finding suggests that gestational exposure to tobacco may present health risks that persist beyond the exposed generation. In one study, Holloway and colleagues found that rats whose mothers were exposed to nicotine, but who were not themselves exposed, were more likely to show insulin resistance and elevated blood pressure postnatally (Holloway, Cuu, Morrison, Gerstein, \& Tarnopolsky, 2007). It is thus plausible that gestational nicotine exposure can influence epigenetic transformations or alterations in maternal physiology which then carry forth independent risks for the development of metabolic syndrome in future generations.

adiposity (Oken, et al., 2005). Though useful, both studies did not control for certain potentially confounding factors including child exposure to maternal gestational alcohol and illicit drugs use, depression, and immigration status. Furthermore, although both studies employed large scale population-based samples, the authors did not employ modern methods for dealing with sample attrition, which can lead to biases in the estimated associations (Graham, 2009).

Child obesity is on the rise in most developing and developed nations (Consultation, 2000). This pandemic rise makes it important to identify subgroups at particular risk. In the present study, we use a population-based birth cohort to examine the association between gestational exposure to tobacco smoke and adiposity by age 10 . Body fat composition, which can be measured through waistline measurements and skin folds, represents a more precise measure of adiposity than BMI because it separates weight due to bone density and muscle mass from fatty body mass (Gutin, 2012; Pouliot et 
al., 1994). ${ }^{18,19}$ Because a number of factors have been shown to potentially explain the relationship between gestational exposure to tobacco smoke and later adiposity, we control for a number of child and family characteristics. Longitudinal studies invariably suffer from sample attrition. Consequently, we also employ modern methods that compensate for study desistence by higher risk participants.

\section{Methods}

\section{Participants}

Analyses were conducted using data from the Quebec Longitudinal Study of Child Development (QLSCD). Children in the QLSCD were randomly selected from a stratified sample of births that occurred between 1997 and 1998 in the French Canadian province of Quebec. The original sample consisted of 2837 infants. At the commencement of the study, however, some children were deemed ineligible $(\mathrm{N}=93)$ or were untraceable due to incorrect coordinates $(\mathrm{N}=172)$ which reduced the sample to 2527. Of the remaining children, 438 refused participation and 14 were unreachable. Beginning at 5 months, 2120 infants were followed up annually for the early childhood phase, which represents $91 \%$ of the eligible target population. Of these, $39 \%$ were firstborn. Baseline measures were taken when children were 5months-old. Follow-up occurred when children were at the end of grades 2 and 4 . For each data collection wave, informed consent was obtained from parents. During the school-aged phase, teachers and children also gave consent. Data on maternal reports of perinatal smoking were available for our entire sample $(n=2110)$.

\section{Outcome Measures: Adiposity}

Skin folds (at 98 months). Trained examiners measured calf, triceps, and abdominal skin folds in millimeters using Harpenden's skin fold caliper (Limbert, Crawford, \& McCargar, 2012). Prior to measuring skin folds, examiners demonstrated the measurement process on themselves. This was done to help ensure that children were as relaxed as possible during the measurement procedure. All measures were taken on the right side of the body. Examiners first marked the exact site to be measured with a marker. At each site three measures were taken to reduce measurement error.

Waist circumference (at 98 and 122 months). Waist circumference was directly assessed by trained examiners. All measures were taken underneath children's clothing and recorded in centimeters using a measuring tape. Children were instructed to stand up as straight as they could and to position their arms either to their side or crossed in front of their chest. Trained examiners located and marked the midway points between the iliac crest and the lowest rib on children's left and right sides. A measuring tape was then placed horizontally across these two points. Measurements were taken after children exhaled normally. In order to reduce measurement error, three measures were taken for each child. An average in centimeters $(\mathrm{cm})$ was then computed from the three measurements. Circumferences were measured in centimeters and rounded to the closest $.01 \mathrm{~cm}$ (C. Fitzpatrick, Pagani, \& Barnett, 2012).

\section{Predictor: Gestational Tobacco Smoke Exposure}

When children were 5-months-old, mothers self-reported their smoking behavior during pregnancy. Mothers were asked two questions related to smoking behavior: (1) Did you smoke during pregnancy? and (2) How many cigarettes did you smoke while pregnant? Self-reports of perinatal smoking have been established with physiological methods (Wong, Shields, Leatherdale, Malaison, \& Hammond, 2012). Based on their responses, mothers were classified into one of three groups: no perinatal smoking (none), 1-9 cigarettes per day (mild), or more than 10 cigarettes per day (heavy). The same or similar groupings have been used in previous studies (Wong, et al., 2012). These 
questions have been validated in previous studies (Caroline Fitzpatrick, Barnett, \& Pagani, 2012; Huijbregts et al., 2006; Huijbregts, Séguin, Zoccolillo, Boivin, \& Tremblay, 2007).

\section{Control Variables}

We considered direct assessments and parent-reported data on pre-existing and baseline individual and family characteristics that could possibly influence both the decision to smoke during pregnancy and adiposity outcomes. Weight for gestational age was calculated using children's birth records. All scores were standardized using child gender and month of pregnancy according to Canadian norms. Children received scores of either 0 (normal weight) or 1 (below the $10^{\text {th }}$ percentile) (Kramer et al., 2001). Child age in months and height was also collected from independent examiners when children were 98 and 122 months.

When children were 5-months-old, mothers reported consumption of alcohol $C 0=$ no alcohol consumption or $1=$ alcohol consumption) and illicit drugs ( $0=$ no drug consumption or $1=$ drug consumption). Mothers also reported their age at child birth, symptoms of depression, high school completion (finishing high school $=1$ and not $=0$ ), immigration status ( $1=$ immigrant, $0=$ non-immigrant), and family configuration (two-parent $=0$ and not $=1$ ) and functioning based on 12 items designed to measure family communication, problem solving, control of disruptive behavior, and demonstrations of affection. Finally, mothers indicated family income in Canadian dollars using the following scale: less than $10 \mathrm{~K} ; 10 \mathrm{~K}$ to 10,$499 ; 15 \mathrm{~K}$ to 19,$999 ; 20 \mathrm{~K}$ to 29,$999 ; 30 \mathrm{~K}$ to 39,$999 ; 40 \mathrm{~K}$ to 49,$999 ; 50 \mathrm{~K}$ to 59,$999 ; 60 \mathrm{~K}$ to 79,999 ; and $80 \mathrm{~K}$ and up.

\section{Data Analytic Strategy}

We estimated a series of ordinary leastsquares regressions in which fourth-grade skin fold and waist circumference are linearly regressed on levels of exposure to perinatal smoking. This estimated relation can be interpreted as the effect of no, mild, or high exposure to perinatal smoking on later adiposity outcomes. To best ensure an unbiased estimation of these associations, we tried to reduce third variable bias by statistically controlling for child and family characteristics likely to account for the relationship between our predictor and outcome variables (Breslau, Paneth, Lucia, \& Paneth-Pollak, 2005; Muthén, Kaplan, \& Hollis, 1987). The reported analyses bear on this adjusted model.

\section{Missing data}

Incomplete data on the outcome variables at 98 and 122 months were managed during the estimation of trajectories using full information maximum likelihood methods in Mplus. ${ }^{25}$ This method adjusts all coefficients in the model based on the observed interrelations in the data, as well as the uncertainty resulting from missingness.

\section{Result}

Table 1 reports descriptive statistics for independent, dependent, and control variables. In the present sample, $75 \%$ of parents reported never smoking during pregnancy, while $14 \%$ and $11 \%$ of parents reported mild and heavy levels of prenatal smoking, respectively. These are similar to worldwide child exposure averages (Breslau, et al., 2005). Children exposed to heavy gestational smoke were more likely to find themselves above the $75^{\text {th }}$ percentile of triceps skin fold sickness, whereas children never exposed were more likely to be below the $50^{\text {th }}$ percentile (Jaworski et al., 2012).

Table 2 reports regression coefficients which estimate the prospective relationship between gestational smoke exposure and child adiposity. Heavy exposure was associated with a $1.997 \mathrm{~mm} \quad(95 \%$ CI between .954 and 3.040) increase in abdominal skin folds, a $1.569 \mathrm{~mm}$ (95\% CI between .685 and 2.453) increase in calf skin

Caroline Fitzpatrick, Tracie A. Barnett and Linda S. Pagani (2015), JMED Research, 
folds, and a $1.141 \mathrm{~mm}$ (95\% CI between .385 and 1.897) increase in triceps skin folds. Heavy exposure was also associated with $1.927 \mathrm{~cm} \mathrm{(95 \%} \mathrm{CI} \mathrm{between} \mathrm{.634} \mathrm{and} \mathrm{3.22)}$ and $3.046 \mathrm{~cm}(95 \%$ CI between 1.81 and 4.282 ) increases in waistline measurements at 98 and 122 months, respectively. Moderate exposure was not significantly associated with adiposity outcomes in children.

\section{Discussion}

Although diet and lifestyle factors are important determinants of children's eventual body composition, they cannot entirely account for the high population prevalence rates of obesity in the population. Consequently, it is likely that additional factors, such as the experience of gestational smoke exposure, may also play a role in the mounting prevalence of adiposity problems facing youth in most developing and developed nations. In the present population-based sample of typically developing children, we found that maternal reports of gestational smoking predict larger waist circumference and skin fold measurements of the abdomen, calves, and triceps by middle childhood. By age 10, children of mothers who smoked more than 10 cigarettes per day were at greater risk of having waists that were on average $3 \mathrm{~cm}$ larger than children of non-smokers. Children of women who smoked moderately did not differ in waist size or skin fold measurements from children of nonsmokers. These findings suggest that heavy gestational cigarette exposure may place children at increased risk for the development of metabolic syndrome.

The skin fold increases associated with exposure to gestational smoking were generally in the area of 1 to 2 millimeters. Although our results have small to moderate effect sizes, they are comparable to skin fold and waist circumference changes found in other studies examining the other known risk factors such as changes in physical activity, television viewing, and early childhood weight gain (Ekelund et al., 2006; C. Fitzpatrick, et al., 2012; Menezes et al.,
2012). Moreover, they may indicate a trajectory of comparatively larger increases in adiposity than is normatively expected.

Pancreatic cell damage and insulin resistance, which contribute to metabolic syndrome, can be observed in the offspring of mice exposed to nicotine (Holloway, et al., 2005). This suggests a possible mechanism through which gestational cigarette exposure may contribute to the development of adiposity and metabolic syndrome in human samples. It is also possible that a mismatch between the fetal expectations of the postnatal environment and the actual postnatal environment experienced may contribute to changes in fetal metabolic programming. For example, gestational tobacco can interfere with the flow of nutrients to the developing fetus. This can then lead to a false expectation of low nutrients in the postnatal environment and incur alterations of the fetal metabolic system in preparation of such an environment (McMillen \& Robinson, 2005).

\section{Limitations}

The present study presents some limitations. First, it is not possible for us to infer a causal relationship between gestational tobacco exposure and later child adiposity. For example, we provide statistical control for some potentially confounding factors such as drinking during pregnancy and family functioning which are likely to provide proxy measures for parental antisocial behaviors and family environment quality. Nevertheless, other unmeasured parental characteristics associated with smoking during gestation could have contributed to later child health status. In particular, future research should examine the extent to which breast feeding, maternal pre-pregnancy BMI, birth weight and child weight gain during the first year of life may explain the observed associations (Weng, Redsell, Swift, Yang, \& Glazebrook, 2012). Second, direct assessments of gestational tobacco smoke exposure were not available in the present study. Consequently, some mothers might have underreported smoking for social desirability motives. Nevertheless, recent data using a large 
representative Canadian sample provide evidence for the validity of self-reports of smoking (Wong, et al., 2012). More specifically, smoking prevalence rates estimated using urine cotinine levels, an accurate and sensitive physiological measure of exposure to cigarette smoke, were found to closely approximate prevalence rates estimated using self-reports.

\section{Implications}

Public health campaigns have been successful in reducing rates of smoking across many Western countries. Despite overall decreases in adult smoking over the past 30 years, decreases have been slower over the past 15 years in Canada and the United States (Freedman, Nelson, \& Feldman, 2012). Furthermore, data suggest that declines in cigarette smoking may be especially slow among young adults, including women of child bearing age, and youth with lower educational attainment (Freedman, et al., 2012; Wennergren et al., 2013). Consequently, the present findings are useful for informing prevention efforts aimed at reducing emerging health disparities.

Child obesity and adiposity represent a consistent health concern. There is an increasing concern for the long-term risks for offspring associated with prenatal maternal smoking (Bruin, et al., 2008). These risks have been documented as far as 33 years of age. This paper helps chart the developmental course toward this long-term risk for obesity. An excess of fatty mass by emerging adolescence places individuals at risk of being overweight or obese in adulthood (Dietz, 2004; Lee et al., 2010; Wright, Emmett, Ness, Reilly, \& Sherriff, 2010). Furthermore, childhood adiposity is associated with a number of adverse physical and mental health problems which can seriously compromise the health and wellbeing of children (Biro \& Wien, 2010; Dietz, 1998; Franks et al., 2010). The World Health Organization regards prevention as the most effective strategy for managing obesity. For this reason, understanding how preventable factors may contribute to childhood adiposity represents an important objective. The present study found evidence that gestational smoke exposure may generate increase risks toward excess adiposity by middle childhood. As a modifiable lifestyle factor, it remains to be seen if developing and targeting preventive interventions and public health campaigns towards reducing or eliminating smoking during pregnancy can help curb the current obesity trend.

\section{Conclusion}

Young women of child-bearing years remain highly represented among smokers. Fortunately, smoke cessation campaigns have been successful in reducing the incidence of maternal smoking, especially among heavy smokers (Hegaard, KjÆrgaard, MØller, Wachmann, \& Ottesen, 2003; Valbös \& Nylander, 1994). Consequently, increasing public health campaigns aimed at discouraging smoking during pregnancy is likely to have positive consequences for population health. In particular, the content of such interventions should emphasize that exposure to prenatal smoking can represent a serious threat to a multitude of long-term health characteristics of children.

\section{Acknowledgement}

The Institut de la statistique du Québec (ISQ) collected and managed the data.

\section{Conflict of Interest}

The authors declare no conflicts of interests.

\section{References}

1. Alberti, K. G., Zimmet, P. and Shaw, J. (2005) "The metabolic syndrome--a new worldwide definition," Lancet, 366(9491) 1059-1062.

2. Barker, D. J. P. (1998) "In utero programming of chronic disease," Clinical Science, 95(2) 115-128.

3. Biro, F. M. and Wien, M. (2010) 
"Childhood obesity and adult morbidities," American Journal of Clinical Nutrition, 91(5) 1499S-1505S.

4. Breslau, N., Paneth, N., Lucia, V. C. and Paneth-Pollak, R. (2005) "Maternal smoking during pregnancy and offspring IQ," International Journal of Epidemiology, 34(5) 1047-1053.

5. Bruin, J. E., Petre, M. A., Lehman, M. A., Raha, S., Gerstein, H. C., Morrison, K. M. and Holloway, A. C. (2008) "Maternal nicotine exposure increases oxidative stress in the offspring," Free Radical Biology and Medicine, 44(11) 1919-1925.

6. World Health Organization. (2000). "Obesity: preventing and managing the global epidemic," World Health Organization technical report series.

7. Dietz, W. H. (1998). "Health consequences of obesity in youth: childhood predictors of adult disease," Pediatrics, 101(2) 518-525.

8. Dietz, W. H. (2004). "Overweight in childhood and adolescence," New England Journal of Medicine, 350 (9) 855-857.

9. DiFranza, J. R., Aligne, C. A. and Weitzman, M. (2004). "Prenatal and postnatal environmental tobacco smoke exposure and children's health," Pediatrics, 113(3) 10071015.

10. Ekelund, U., Brage, S., Froberg, K., Harro, M., Anderssen, S. A., Sardinha, L. B., . . . Andersen, L. B. (2006). "TV viewing and physical activity are independently associated with metabolic risk in children: the European Youth Heart Study," PLoS Medicine, 3(12) 2449-2457.

11. Fitzpatrick, C., Barnett, T. A. and Pagani, L. S. (2012). "Parental bad habits breed bad behaviors in youth: exposure to gestational smoke and child impulsivity," International Journal of Psychophysiology. doi: 10.1016/j.ijpsycho.2012.11.006.

12. Fitzpatrick, C., Pagani, L. S. and Barnett,
T. A. (2012). "Early childhood television viewing predicts explosive leg strength and waist circumference by middle childhood," International Journal of Behavioral Nutrition and Physical Activity, 9(1) doi:10.1186/14795868-9-87.

13. Franks, P. W., Hanson, R. L., Knowler, W. C., Sievers, M. L., Bennett, P. H., and Looker, H. C. (2010). "Childhood obesity, other cardiovascular risk factors, and premature death," New England Journal of Medicine, 362 (6) 485-493.

14. Freedman, K. S., Nelson, N. M. and Feldman, L. L. (2012). "Smoking initiation among young adults in the United States and Canada, 1998-2010: a systematic review," Preventing Chronic Disease, 9 doi: http://dx.doi.org/10.5888/pcd9.110037

15. Gao, Y. J., Holloway, A. C., Zeng, Z., Lim, G. E., Petrik, J. J., Foster, W. G., and Lee, R. M. K. W. (2005). "Prenatal exposure to nicotine causes postnatal obesity and altered perivascular adipose tissue function," Obesity Research, 13(4) 687-692.

16. Graham, W. J. (2009). "Missing data: making it work in the real world," Annual Review of Psychology, 60 549-576.

17. Gutin, B. (2012). “Child obesity can be reduced with vigorous activity rather than restriction of energy intake," Obesity, 16(10) 2193-2196.

18. Hegaard, H. K., KjÆrgaard, H., MØller, L. F., Wachmann, H. and Ottesen, B. (2003). "Multimodal intervention raises smoking cessation rate during pregnancy," Acta obstetricia et Gynecologica Scandinavica, 82(9) 813-819.

19. Hirschler, V., Aranda, C., Calcagno, M., Maccalini, G. and Jadzinsky, M. (2005). "Can waist circumference identify children with the metabolic syndrome?" Archives of Pediatrics and Adolescent Medicine, 159(8) 740-744.

20. Holloway, A. C., Cuu, D. Q., Morrison, K.

Caroline Fitzpatrick, Tracie A. Barnett and Linda S. Pagani (2015), JMED Research, 
M., Gerstein, H. C. and Tarnopolsky, M. A. (2007). "Transgenerational effects of fetal and neonatal exposure to nicotine," Endocrine, 31(3) 254-259.

21. Holloway, A. C., Lim, G. E., Petrik, J. J., Foster, W. G., Morrison, K. M. and Gerstein, H. C. (2005). "Fetal and neonatal exposure to nicotine in Wistar rats results in increased beta cell apoptosis at birth and postnatal endocrine and metabolic changes associated with type 2 diabetes," Diabetologia, 48(12) 2661-2666.

22. Huijbregts, S., Séguin, J., Zelazo, P., Parent, S., Japel, C. and Tremblay, R. (2006) "Interrelations between maternal smoking during pregnancy, birth weight and sociodemographic factors in the prediction of early cognitive abilities," Infant and Child Development, 15(6) 593-607.

23. Huijbregts, S., Séguin, J., Zoccolillo, M., Boivin, M. and Tremblay, R. (2007). "Associations of maternal prenatal smoking with early childhood physical aggression, hyperactivity-impulsivity, and their cooccurrence," Journal of Abnormal Child Psychology, 35(2) 203-215.

24. Huizink, A. C. and Mulder, E. J. H. (2006). "Maternal smoking, drinking or cannabis use during pregnancy and neurobehavioral and cognitive functioning in human offspring," Neuroscience and Biobehavioral Reviews, 30(1) 24-41.

25. Jaworski, M., Kułaga, Z., Płudowski, P., Grajda, A., Gurzkowska, B., Napieralska, E., ... Litwin, M. (2012). "Population-based centile curves for triceps, subscapular, and abdominal skinfold thicknesses in Polish children and adolescents-the OLAF study," European Journal of Pediatrics, 171(8) 12151221.

26. Kramer, M., Platt, R., Wen, S., Joseph, K., Allen, A., Abrahamowicz, M., . . . Breart, G. (2001). "A new and improved populationbased Canadian reference for birth weight for gestational age," Pediatrics, 108(2) e35.
27. Lee, J. M., Pilli, S., Gebremariam, A., Keirns, C. C., Davis, M. M., Vijan, S., . . Gurney, J. G. (2010). "Getting heavier, younger: trajectories of obesity over the life course," International Journal of Obesity, 34(4) 614623.

28. Limbert, J., Crawford, S. M. and McCargar, L. J. (2012). "Estimates of the prevalence of obesity in Canadian children," Obesity Research, 2(4) 321-327.

29. McMillen, I. C. and Robinson, J. S. (2005). "Developmental origins of the metabolic syndrome: prediction, plasticity, and programming," Physiological Reviews, 85(2) 571-633.

30. Menezes, A. M. B., Hallal, P. C., Dumith, S. C., Matijasevich, A. M., Araújo, C. L. P., Yudkin, J., . . Victora, C. G. (2012). "Adolescent blood pressure, body mass index and skin folds: sorting out the effects of early weight and length gains," Journal of Epidemiology and Community Health, 66(2) 149-154.

31. Muthén, B., Kaplan, D. and Hollis, M. (1987). "On structural equation modeling with data that are not missing completely at random," Psychometrika, 52(3) 431-462.

32. Nordentoft, M., Lou, H. C., Hansen, D., Nim, J., Pryds, O., Rubin, P. and Hemmingsen, R. (1996). "Intrauterine growth retardation and premature delivery: the influence of maternal smoking and psychosocial factors," American Journal of Public Health, 86(3) 347354.

33. Oken, E., Huh, S. Y., Taveras, E. M., RichEdwards, J. W. and Gillman, M. W. (2005). "Associations of maternal prenatal smoking with child adiposity and blood pressure," Obesity, 13(11) 2021-2028.

34. Pouliot, M. C., Després, J. P., Lemieux, S., Moorjani, S., Bouchard, C., Tremblay, A., . . . Lupien, P. J. (1994). "Waist circumference and abdominal sagittal diameter: best simple anthropometric indexes of abdominal visceral adipose tissue accumulation and related cardiovascular risk in men and

Caroline Fitzpatrick, Tracie A. Barnett and Linda S. Pagani (2015), JMED Research,

DOI: $10.5171 / 2015.791127$ 
women," American Journal of Cardiology, 73(7) 460-468.

35. Power, C. and Jefferis, B. J. M. H. (2002). "Fetal environment and subsequent obesity: a study of maternal smoking," International Journal of Epidemiology, 31(2) 413-419.

36. Valbös, A. and Nylander, G. (1994). "Smoking cessation in pregnancy: intervention among heavy smokers," Acta Obstetricia et Gynecologica Scandinavica, 73(3) 215-219.

37. Weng, S. F., Redsell, S. A., Swift, J. A., Yang, M. and Glazebrook, C. P. (2012). "Systematic review and meta-analyses of risk factors for childhood overweight identifiable during infancy," Archives of Disease in Childhood, 97(12) 1019-1026.
38. Wennergren, G., Ekerijung, L., Alm, B., Bjerg, A., Lötvall, J. and Lundbäck, B. (2013). "Alarmingly high prevalence of smoking and symptoms of bronchitis in young women in Sweden: a population-based questionnaire study," Primary Care Respiratory Journal, 22(2) 214-220.

39. Wong, S. L., Shields, M., Leatherdale, S., Malaison, E. and Hammond, D. (2012). "Assessment of validity of self-reported smoking status," Health Reports, 23(1) 47-53.

40. Wright, C. M., Emmett, P. M., Ness, A. R., Reilly, J. J. and Sherriff, A. (2010). "Tracking of obesity and body fatness through midchildhood," Archives of Disease in Childhood, 95(8) 612-617 
Table 1: Descriptive statistics for independent, dependent, and control characteristics

\begin{tabular}{|c|c|c|c|}
\hline & Mean (SD) & Min & Max \\
\hline \multicolumn{4}{|c|}{ Independent Variable (Gestational Tobacco) } \\
\hline No perinatal smoking & $75 \%$ & & \\
\hline Mild perinatal smoking & $11 \%$ & & \\
\hline Heavy perinatal smoking & $14 \%$ & & \\
\hline \multicolumn{4}{|c|}{ Dependent Variables (Child Adiposity) } \\
\hline Abdomen $98 \mathrm{mo}(\mathrm{mm})$ & $11.59(6.77)$ & .77 & 60.10 \\
\hline Calf $98 \mathrm{mo}(\mathrm{mm})$ & $12.58(5.67)$ & .83 & 55.00 \\
\hline Triceps $98 \mathrm{mo}(\mathrm{mm})$ & $12.58(4.92)$ & .50 & 44.00 \\
\hline Waistline $98 \mathrm{mo}(\mathrm{cm})$ & $57.55(8.65)$ & 19.50 & 103.5 \\
\hline Waistline $122 \mathrm{mo}(\mathrm{cm})$ & $64.69(8.52)$ & 48.00 & 114.00 \\
\hline \multicolumn{4}{|c|}{ Control Variables } \\
\hline Sex & & & \\
\hline Boys & $51 \%$ & & \\
\hline Girls & $49 \%$ & & \\
\hline Perinatal drinking & $35.6 \%$ & & \\
\hline Perinatal drug use & $1.3 \%$ & & \\
\hline Low birth weight & $7.7 \%$ & & \\
\hline
\end{tabular}

Caroline Fitzpatrick, Tracie A. Barnett and Linda S. Pagani (2015), JMED Research, DOI: $10.5171 / 2015.791127$ 


\begin{tabular}{|c|c|c|c|}
\hline & Mean (SD) & Min & Max \\
\hline \multicolumn{4}{|c|}{ Control Variables (continued) } \\
\hline Maternal depression & $1.41(1.35)$ & 0 & 9.30 \\
\hline \multicolumn{4}{|l|}{ Maternal immigration } \\
\hline Immigrant & $12 \%$ & & \\
\hline Non-immigrant & $88 \%$ & & \\
\hline Maternal BMI & $23.63(4.60)$ & 14.17 & 47.34 \\
\hline Maternal age & $29.28(5.20)$ & 16 & 44.50 \\
\hline \multicolumn{4}{|l|}{ Maternal education } \\
\hline High school diploma & $82 \%$ & & \\
\hline No diploma & $18 \%$ & & \\
\hline \multicolumn{4}{|l|}{ Family configuration } \\
\hline Intact & $81 \%$ & & \\
\hline Non-intact & $19 \%$ & & \\
\hline Family functioning & $1.72(1.47)$ & 0 & 10 \\
\hline Income & $5.81(2.30)$ & 1 & 9 \\
\hline Height in cm (grade 2) & $128.00(5.64)$ & 108.00 & 150.00 \\
\hline Child age (grade 2) & $98.04(3.12)$ & 92.4 & 104.4 \\
\hline Child age (grade 4) & $121.99(3.14)$ & 116 & 128 \\
\hline
\end{tabular}

Caroline Fitzpatrick, Tracie A. Barnett and Linda S. Pagani (2015), JMED Research, DOI: $10.5171 / 2015.791127$ 
Table 2: Sample characteristics according to smoking exposure

\begin{tabular}{|c|c|c|c|}
\hline & No smoking & Mild smoking & Heavy smoking \\
\hline & $\mathrm{M}(\mathrm{SD})$ & $\mathrm{M}(\mathrm{SD})$ & $\mathrm{M}(\mathrm{SD})$ \\
\hline Abdomen (mm) & $11.21(6.28)$ & $11.47(7.74)$ & $13.69(8.02)$ \\
\hline Calf $(\mathrm{mm})$ & $12.16(5.19)$ & $12.49(5.95)$ & $13.84(7.46)$ \\
\hline Triceps (mm) & $12.35(4.50)$ & $12.84(5.88)$ & $13.62(6.01)$ \\
\hline Waistline $98 \mathrm{mo}(\mathrm{cm})$ & $57.27(8.18)$ & $58.04(8.17)$ & $58.67(11.07)$ \\
\hline Waistline 122 mo (cm) & $64.14(7.92)$ & $64.98(8.99)$ & $67.57(10.58)$ \\
\hline Sex (\% male) & $51 \%$ & $50 \%$ & $49 \%$ \\
\hline Perinatal drinking (\% yes) & $34 \%$ & $40 \%$ & $40 \%$ \\
\hline Perinatal drug use (\% yes) & $0 \%$ & $2 \%$ & $6 \%$ \\
\hline Low birth weight & $6 \%$ & $10 \%$ & $16 \%$ \\
\hline Maternal depression & $1.34(1.31)$ & $1.54(1.40)$ & $1.66(1.42)$ \\
\hline Maternal immigration (\% yes) & $3 \%$ & $5 \%$ & $15 \%$ \\
\hline Maternal BMI & $23.71(4.48)$ & $23.36(5.11)$ & $23.42(4.82)$ \\
\hline Maternal age (years) & $29.76(5.04)$ & $27.67(5.32)$ & $28.09(5.63)$ \\
\hline $\begin{array}{l}\text { Maternal education ( } \% \text { no } \\
\text { diploma) }\end{array}$ & $13 \%$ & $26 \%$ & $40 \%$ \\
\hline $\begin{array}{l}\text { Family configuration (\% non- } \\
\text { intact) }\end{array}$ & $15 \%$ & $30 \%$ & $36 \%$ \\
\hline Family functioning & $1.64(1.44)$ & $2.06(1.54)$ & $1.82(1.50)$ \\
\hline & $6.04(2.26)$ & $5.23(2.36)$ & $4.77(2.14)$ \\
\hline
\end{tabular}

Caroline Fitzpatrick, Tracie A. Barnett and Linda S. Pagani (2015), JMED Research, DOI: $10.5171 / 2015.791127$ 


\begin{tabular}{|l|l|l|l|}
\hline Income & & & \\
\hline Height in cm (grade 2) & $127.99(5.50)$ & $128.18(5.70)$ & $127.91(6.36)$ \\
\hline Child age (grade 4) & $121.85(3.22)$ & $121.86(3.44)$ & $121.88(3.15)$ \\
\hline
\end{tabular}

Table 3: Beta coefficients and 95\% confidence intervals reflecting the relationship between gestational smoke exposure and fitness indicators at 74 and 120 months

\begin{tabular}{|l|c|c|c|c|c|}
\hline & \multicolumn{3}{|c|}{ Skin Folds } & \multicolumn{2}{c|}{ Waistline } \\
\hline Predictors & Abdomen & Calf & Triceps & 98 months & 120 months \\
\hline & & & & & \\
\hline Heavy & $1.997(.954-$ & $1.569(.685-$ & $1.141(.385-$ & $1.927(.634-$ & $3.046(1.81-$ \\
smoking & $3.040)^{* * *}$ & $2.453)^{* *}$ & $1.897)^{* *}$ & $3.22)^{* *}$ & $4.282)$ \\
\hline Mild & $-.037(-.137-$ & $.062(-.083-$ & $.356(-.446-$ & $.701(-.660-$ & $.549(-.760-$ \\
smoking & $1.062)$ & $.998)$ & $1.158)$ & $2.075)$ & $1.859)$ \\
\hline R squared & 1.39 & .115 & .140 & .186 & .284 \\
\hline
\end{tabular}

Note. Models control for concurrent child height, age in months, sex, and weight for gestational age, perinatal exposure to alcohol and illicit drugs, family functioning, maternal age, depression, immigration status, high school completion, family configuration and income. Asterices denote significance at ${ }^{* *} \mathrm{P}<.01$ and ${ }^{* * *} \mathrm{P}<.0001$. 